\title{
Inseguridad agraria, identidades y conflictos en un territorio campesino enclavado en un área natural protegida: el caso de Los Laureles, Chiapas
}

\section{Agrarian Insecurity, Identities and Conflicts in a Peasant Territory Nestled in a Natural Protected Area: The Case of Los Laureles, Chiapas}

\author{
Juana Cruz-Morales* (D) https://orcid.org/0000-0002-5410-2702 \\ Ana Gabriela Trujillo-Díaz (iD https://orcid.org/0000-0001-6576-5897 \\ Luis E. García-Barrios ${ }^{* *}$ (iD) https://orcid.org/0000-0001-8227-7748
}

\begin{abstract}
Resumen
Los pobladores que viven sin reconocimiento agrario en las reservas de la biosfera construyen identidades, enfrentan conflictos, desafíos internos y externos para construir su territorio, los cuales dificultan la regularización agraria. Los campesinos de Los Laureles buscan asegurar su permanencia en el territorio refuncionalizando de manera continua su identidad frente a otros actores. El objetivo de esta investigación es identificar y analizar dichas identidades mediante el recorrido diacrónico y las entrevistas e historias de vida en profundidad. Los resultados muestran que la mayoría de los entrevistados han forjado identidades multidimensionales para enfrentar su inseguridad cotidiana (por ejemplo, son a la vez huérfanos, peones, agricultores, pobres y custodios de la naturaleza). Aunque limitado a un poblado, el estudio explora una condición común en otras reservas. Su originalidad radica en visibilizar las historias de vida e identidades que refuerzan la irregularidad agraria. Se concluye que la autopercepción como pobres marginados reduce su capacidad de agencia y sus esfuerzos para superar esta irregularidad y sus consecuencias.

Palabras clave: comunidad marginal; asentamientos irregulares; recorrido diacrónico; historia de vida; área natural protegida; identidad social.
\end{abstract}

\begin{abstract}
People dwelling without agrarian rights in spaces recently declared Biosphere Reserves face internal and external conflicts and challenges that affect their identities and reinforce their condition as "irregulars". At Los Laureles, rural families continu ously redefine their multidimensional identities in an effort to justify their permanence and ensure a livelihood. This research objective is to analyze such identities; for this purpose, we used diachronic tour, detailed life histories, and indepth interviews. Results show that most interviewees have forged multidimensional identities to deal with daily insecurity (i.e. they see themselves simultaneously as orphans, peons, farmers, poor, and guardians of nature in reserves). Although limited to one case study, it explores consequences of irregularity, a common agrarian condition in reserves. Its originality lies in highlighting life histories and identities that reinforce irregularity itself. Conclusions lead to think that Los Laureles dwellers mainly perceive themselves as poor-alienated and thus reduce their agency and their capacity to collaborate internally in order to overcome irregularity and its consequences.

Keywords: marginalized communities; irregular settlements; diachronic tour; life history; protected natural area; social identity.
\end{abstract}

Cómo citar: Cruz-Morales, J., Trujillo-Díaz, A. G., y García-Barrios, L. E. (2020). Inseguridad agraria, identidades y conflictos en un territorio campesino enclavado en un área natural protegida: el caso de Los Laureles, Chiapas. región y sociedad, 32, el235. doi: I0.22198/ rys2020/32//235

*Autora para correspondencia. Universidad Autónoma Chapingo, Posgrado en Desarrollo Rural Regional Sede Chiapas. Calle Diego de Mazariegos Núm. 85, Barrio La Merced, C. P. 29290, San Cristóbal de las Casas, Chiapas, México. Correo electrónico: cruz_juanam@yahoo.com.mx

** Universidad Autónoma Chapingo, Posgrado en Desarrollo Rural Regional Sede Chiapas. Calle Diego de Mazariegos Núm. 85, Barrio La Merced, C. P. 29290, San Cristóbal de las Casas, Chiapas, México. Correo electrónico: agtrujillochapingo@gmail.com

*** Dirección Regional Sureste del Consejo Nacional de Ciencia y Tecnología. Carretera Panamericana y Periférico Sur s. n., C. P. 29200, San Cristóbal de las Casas, Chiapas, México. Correo electrónico: luis.garciabarrios@gmail.com 


\section{Introducción}

Uno de los mayores problemas en el medio rural es la inseguridad agraria (Organización de las Naciones Unidas para la Alimentación y la Agricultura [FAO], 2003; Torres-Mazuera, Fernández-Mendiburo y Gómez, 2018), sobre todo cuando hay factores y decisiones externas que afectan los derechos agrarios de los pueblos. Si bien es cierto que en México el Programa de Certificación de Derechos Ejidales y Titulación de Solares (PROCEDE) dio certidumbre agraria, es importante señalar que sólo se beneficiaron aquellos individuos que contaban con derechos agrarios. El PROCEDE no favoreció a los poseedores de tierras que permanecen sin dichos derechos. Así, pese a las promesas de la reforma al artículo 27 constitucional del año 1992, la incertidumbre agraria continúa para los denominados asentamientos irregulares.

Por otro lado, el decreto de áreas naturales protegidas (ANP) es un factor que contribuye a la inseguridad agraria debido a que centraliza el control territorial al poner en manos de organizaciones gubernamentales y no gubernamentales el manejo del territorio. Con frecuencia la designación de ANP es parte de las estrategias de desarrollo del gobierno basadas en la noción de control del uso de la tierra (Anaya y Espírito-Santo, 2018). Las consecuencias agrarias del decreto de una ANP son varias, pero es importante señalar que con el decreto se reconocen asentamientos regulares (legalizados) e irregulares (no legalizados). Es decir, si la población demuestra la legal y legítima posesión del predio en donde se encuentra el asentamiento, es regular; en caso contrario, se considera irregular. Esta dinámica ha provocado la emergencia de una nueva identidad, los irregulares, la cual acarrea fuertes conflictos al interior de los territorios. La problemática surge luego del decreto de las ANP, pues los asentamientos irregulares quedan imposibilitados para transitar hacia la regularización de la tenencia de sus tierras, debido a las normatividades impuestas mediante el decreto de conservación.

El ejido nació con la revolución mexicana (1910), y antes de 1992 se empleó como un instrumento del Estado para redistribuir las tierras (Pérez y Mackinlay, 2015). Por más de siete décadas la Reforma Agraria realizó el reparto de tierras y "para 1991, antes de la enmienda al artículo 27 constitucional para ponerle fin al reparto agrario, se habían repartido más de dos terceras partes de las tierras y bosques de México" (Kourí, 2015, p. 1). Con las reformas a dicho artículo la propiedad social, que se estimaba en "70\% de la tierra [integrada por] ejidos y comunidades agrarias" (Merino y Martínez, 2014, p. 21-22), se trasformó y "en la actualidad [la propiedad social] sólo conserva la [característica] de imprescriptibilidad; ahora se trata de una propiedad alienable, transmisible, embargable, divisible y convertible” (Pérez y Mackinlay, 2015, p. 57). Lo que ha provocado que en los últimos diez años la superficie de ejidos y comunidades se desplome: "[pasó de] 51.1\% del total nacional en el 2007 a 47.3\% en el 2016" (Cruz-Vargas, 2017, s. p.).

Antes de concluir el reparto agrario, un grupo de campesinos sin tierra podía -en teoría - tener acceso a ésta mediante la posesión y la gestión ante las 
autoridades de la antigua Secretaría de la Reforma Agraria (SRA). Sin embargo, algunos campesinos poseedores de tierra no lograron llevar a cabo los trámites para regularizar sus tierras antes de 1992, cuando se diera por terminado el reparto agrario, por lo que no están constituidos conforme a la ley. A la fecha (2020) aún existen grupos de campesinos que se posesionaron de terrenos baldíos o nacionales, pero que no lograron gestionar la resolución presidencial; a estas personas se les conoce de manera legal como "nacionaleros", y a su terreno como "asentamiento irregular".

El concepto nacionaleros surgió cuando los terrenos propiedad de la nación fueron ocupados por poblaciones campesinas o indígenas; los terrenos nacionales son aquellos sobre los que el Ejecutivo federal puede ejercer actos de administración y dominio (Secretaría de Desarrollo Territorial y Urbano y Procuraduría Agraria, 2014). Por otro lado, un asentamiento humano es "el establecimiento de un conglomerado demográfico, con el conjunto de sus sistemas de convivencia; en un área físicamente localizada, considerando dentro de la misma los elementos naturales y las obras materiales que lo integran" (Diario Oficial de la Federación [DOF], 28 de noviembre de 2016). El asentamiento humano está constituido conforme a la ley cuando aparece en el Registro Público de la Propiedad, o en el caso de los asentamientos rurales si cuentan con un certificado agrario expedido por la extinta SRA. En este sentido, cuando un asentamiento humano no cuenta con su escritura pública o su certificado agrario se dice que no está constituido ante la ley y se le conoce como "asentamiento irregular” (Ruiz-Gómez, 2006).

Existen en Chiapas cerca de 432600 hectáreas (ha) sin resolución agraria, distribuidas en 69 municipios de los 119 que hay en esta entidad federativa; los municipios con más casos son Ostuacán (278), Ocozocuautla (192), Tonalá (172), Pijijiapan (158), Villacorzo (128) y Villaflores (104). Sin embargo, estos 1032 casos representan sólo $30 \%$ del total de los predios sin resolución agraria, el restante $70 \%$ se distribuye en otros municipios ${ }^{1}$ (Secretaría de Desarrollo Agrario, Territorial y Urbano en Chiapas, 2017; Trujillo-Díaz, Cruz-Morales, García-Barrios y Pat, 2018).

Ante este escenario, el objetivo de esta investigación es identificar y analizar las identidades de los campesinos que durante el reparto agrario no obtuvieron el reconocimiento legal de sus posesiones en la reserva de la biosfera La Sepultura y, al defender el territorio apropiado, enfrentan conflictos y desafíos tanto internos como externos que dificultan la regularización. Para ello, se estudia el caso de la comunidad Los Laureles - señalada como irregular-, localizada en el municipio de Villaflores, Chiapas, México, misma que fue integrada

\footnotetext{
1 Villa Comaltitlán, Palenque, Cintalapa, Tapachula, Ocosingo, Tecpatán, Ángel Albino Corzo, Unión Juárez, Pichucalco, Motozintla, Escuintla, La Concordia, Reforma, Las Margaritas, Tuxtla Gutiérrez, Arriaga, Comitán, La Libertad, Acapetahua, Huixtla, Mapastepec, Villa Las Rosas, Acacoyagua, San Fernando, Berriozábal, La Trinitaria, Sunuapa, Amatán, Bochil, Jiquipilas, Unión Juárez, Solistahuacán, Suchiate, Villa Corzo, Ixhuatán, Acala, Copainalá, Cacahoatán, Catazajá, Chicomuselo, Mazatán, Siltepec, Solosuchiapa, Coapilla, Huehuetán, Independencia, Venustiano Carranza, Metapa, Altamirano, Frontera Hidalgo, Pantelhó, Socoltenango, Chiapa de Corzo, Pantepec, Salto de Agua, Tuxtla Chico, Tzimol, Amatenango La Frontera, Chalchihuitán, Frontera Comalapa, Ixtacomitán, Ixtapangajoya, San Cristóbal de Las Casas.
} 
a la Reserva de la Biosfera La Sepultura (REBISE). Para comprender las causas que ocasionaron que la población no obtuviera la resolución presidencial antes del decreto de la REBISE en 1995, se utilizó una metodología que combinó lo siguiente: recorrido diacrónico, entrevistas e historias de vida en profundidad realizadas durante 2016 y 2017.

\section{Puentes teóricos en la construcción del territorio}

El territorio se define como el espacio del que se ha apropiado un grupo social y lo valoriza para asegurar su reproducción y satisfacer sus necesidades fisiológicas básicas, seguridad, pertenencia, afecto, estima, reconocimiento y autorrealización (Cruz-Morales, 2014a; Giménez, 2007; Mazurek, 2006). El territorio es un recurso producido, manejado y valorado en forma colectiva; para esto se requiere de la construcción de decisiones colectivas y del manejo de recursos compartidos, por ejemplo, la infraestructura, los caminos y las áreas de uso común (Giménez, 2007). Las siete características destacadas del territorio son:

1) Toda relación social tiene ocurrencia en el territorio y se expresa como territorialidad. El territorio es el escenario de las relaciones sociales y no solamente el marco espacial que delimita el dominio soberano de un Estado. 2) El territorio es un espacio de poder, de gestión y de dominio del Estado, de individuos, de grupos y organizaciones y de empresas locales, nacionales y multinacionales. 3) Es una construcción social y nuestro conocimiento del mismo implica el conocimiento del proceso de su producción. 4) La actividad espacial de los actores es diferencial y por lo tanto su capacidad real y potencial de crear, recrear y apropiar territorio es desigual. 5) En el espacio concurren y se sobreponen distintas territorialidades locales, regionales, nacionales y mundiales, con intereses distintos, con percepciones, valoraciones y actitudes territoriales diferentes, que generan relaciones complementarias, de cooperación y conflicto. 6) El territorio no es fijo, sino móvil, mutable y desequilibrado. La realidad geosocial es cambiante y requiere permanentemente nuevas formas de organización territorial. 7) El sentido de pertenencia e identidad, el de conciencia regional, al igual que el ejercicio de la ciudadanía y de acción ciudadana, sólo adquieren existencia real a partir de su expresión de territorialidad. En un mismo espacio se sobreponen múltiples territorialidades y múltiples lealtades. (Montañez y Delgado, 1998, pp. 122-123)

La identidad cultural encierra el sentido de pertenencia de una persona a un grupo social, que puede ser la familia, la comunidad o la vecindad, con el cual se comparten rasgos culturales, como creencias, valores, tradiciones y costumbres. En la sociología y en la antropología la identidad surge como diferenciación y como reafirmación de un sujeto frente al otro. 
La identidad puede conceptualizarse como un proceso subjetivo (y frecuentemente autorreflexivo) por el que los sujetos definen su diferencia de otros sujetos (y de su entorno social), mediante la autoasignación de un repertorio de atributos culturales frecuentemente valorizados y relativamente estables en el tiempo. (Giménez, 2007, p. 61)

La identidad, a diferencia de la capacidad de agencia, se centra en aspectos simbólicos del sujeto, actor o agente que mediante su identidad hace un recuento de valorizaciones, simbolismos y significados sobre el grupo al que pertenece (Scandroglio, López y San José, 2008). Comprende también sus conocimientos y actividades, por lo que en una persona se pueden encontrar identidades múltiples dependiendo de su acercamiento con una actividad o con un grupo productivo. Así, hay personas que se consideran jornaleros, maiceros, ganaderos, cafetaleros; hay otros que por su situación económica se consideran pobres; algunos que por sus creencias religiosas o prácticas espirituales se autonombran católicos, budistas o pentecostés; y también aquellos que por su reconocimiento agrario se identifican como ejidatarios, comuneros, rancheros o baldíos.

\section{Los Laureles: territorio campesino no legalizado enclavado en la REBISE}

La comunidad Los Laureles fue fundada en 1987. Se encuentra en la región suroeste del estado de Chiapas y al noroeste de la Sierra Madre, en el municipio de Villaflores, Chiapas, México (véase figura 1). Está ubicada en las coordenadas $93^{\circ} 41^{\prime} 46^{\prime \prime}$ longitud oeste y 167'05" latitud norte, a una altitud de 1160 metros sobre el nivel del mar (msnm) donde nace un pequeño arroyo que vierte sus aguas al río El Tablón. Al norte colinda con terrenos nacionales ocupados por la zona núcleo Tres Picos, la más grande en la REBISE; al sur, con el Nuevo Centro de Población Tierra y Libertad; al este, con el Nuevo Centro de Población El Triunfo y Las Marías Ampliación del ejido Los Ángeles; y al oeste, con el Nuevo Centro de Población Viva Chiapas (DOF, 13-03-2002). Por el hecho de estar dentro del polígono de una reserva de la biosfera, se sobreponen en este territorio distintas territorializaciones, entre las que destacan las nacionales (decreto y leyes ambientales) y las internacionales (Programa El Hombre y la Biosfera).

Los Laureles es un territorio porque es un lugar donde se realizan las acciones de apropiación del espacio, se desencadenan los poderes, las fuerzas y las debilidades de los campesinos; es un espacio del que los campesinos se han apropiado y lo valorizan (Cruz-Morales, 2014a; Giménez, 2007; Mazurek, 2006; Porto-Goncalves, 2009). El territorio “está vinculado siempre con el poder y con el control de procesos sociales mediante el control del espacio" (Haesbaert, 2013, p. 13). El poder se entiende como: 
Figura 1. Macrolocalización y microlocalización de Los Laureles

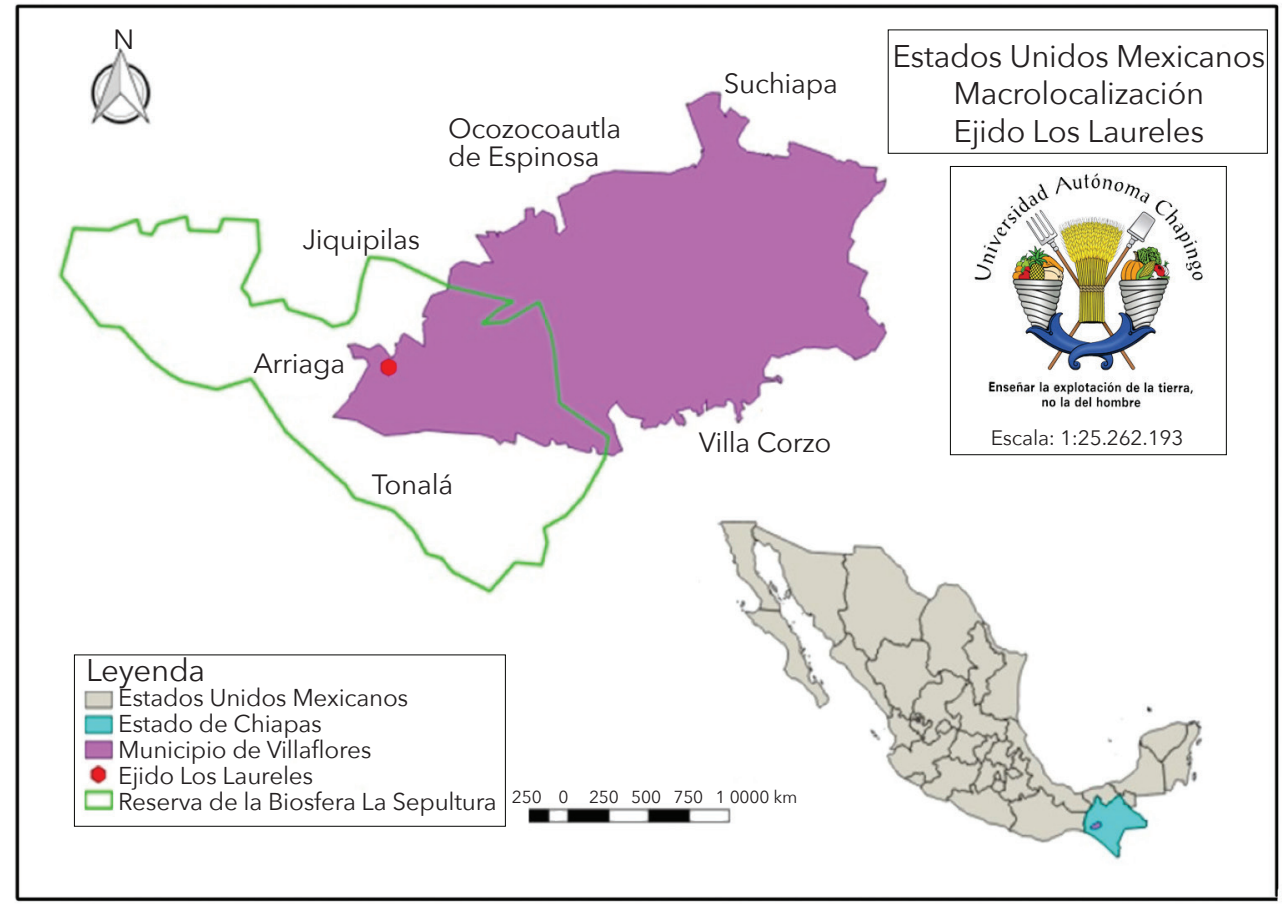

Fuente: elaboración propia a través del programa QGIS con información recopilada en la base de datos del INEGI (2010).

Una relación en la cual unos guían y conducen las acciones de los otros, es decir el poder no sólo reprime, sino también induce, seduce, facilita, dificulta, amplía, limita y hasta puede prohibir, aunque no es la prohibición la forma más importante, ni siquiera la privilegiada. (García, 2005, p. 37)

En las 827 hectáreas que ocupa Los Laureles se encuentran varios tipos de vegetación que configuran un mosaico diversificado de bosque mesófilo de montaña, bosque de pino encino y galerías riparias con predominancia del árbol liquidámbar (Liquidamber styraciflua). Estos ecosistemas son de gran importancia para la conservación de la zona núcleo y para la política ambiental de la Comisión Nacional de Áreas Naturales Protegidas (CONANP). También son importantes porque son el instrumento de poder con el que los campesinos de Los Laureles negociaron su permanencia ante esa Comisión. Al mismo tiempo que los ecosistemas contenidos en este territorio se convirtieron en un espacio de poder y de dominio del Estado a través de leyes ambientales. Además, son un espacio de poder y de gestión para los campesinos.

La región de la REBISE en el municipio de Villaflores es conocida como la Cuenca Alta del Río El Tablón (CART) y está integrada por 17 localidades (30 de 
Noviembre, Nuevo Chilón, Josefa Ortiz, La Sombra de La Selva, Flores Magón, Los Ángeles, El Triunfo, Los Laureles, Tierra y Libertad, Viva Chiapas, Nueva Independencia, Tres Picos, California, El Paraíso, Nueva Independencia, Villahermosa y Niquidámbar). El periodo de reparto agrario en la CART inició en 1959 y finalizó en 1991; sin embargo, durante este periodo dos comunidades (El Triunfo y Los Laureles) de las 17 no lograron regularizarse. Además, el gobierno fomentó un fideicomiso agrario con el que se asentó de forma legal la localidad 30 de Noviembre (Cruz-Morales, 2014a).

Se eligió estudiar el caso de Los Laureles porque es un asentamiento representativo de la relación entre la inseguridad agraria y la política de conservación de los recursos naturales, además del interés de los campesinos de esta localidad para que se realizara esta investigación.

Según el censo local realizado por el comisariado de Los Laureles, en el poblado hay 27 familias y una población total de 217 habitantes (Censo local, 2016-2017) que organizan su vida cotidiana en dos barrios conocidos en la localidad como barrio pobre y barrio rico y están divididos en tres grupos: I (11 familias), II (9 familias) y III (7 familias). Más adelante se realiza una caracterización de la población.

\section{Metodología}

La metodología utilizada se basó en el estudio de caso en combinación con el recorrido diacrónico aplicado a los campesinos de Los Laureles, entrevistas en profundidad realizadas con cuatro actores clave y 15 historias de vida (ocho de hombres y siete de mujeres) que fueron grabadas de forma digital y transcritas para encontrar patrones sobre los siguientes aspectos: identidad, actividades productivas, valores relacionados con la tierra y la familia, conflictos y relaciones de poder. Con estas variables se creó una base de datos en el programa Excel, con el fin de procesar la información. Además, se empleó un enfoque cualitativo-reflexivo caracterizado por la observación participante (Vasilachis, 2006), que incluye recorridos realizados por las parcelas, los traspatios y los sitios de bosque; también se observaron reuniones y asambleas en las que participaron campesinos hombres, mujeres, jóvenes, niños y niñas. Se incluye además el diálogo entre la población y los investigadores durante el periodo 2010-2017. Se revisó el expediente de Los Laureles que se encuentra en el Archivo Agrario Nacional, delegación Chiapas. Así mismo se revisaron los documentos referentes a los trámites agrarios realizados entre 1987 y 2017 . Estos documentos fueron ordenados por fecha (véase figura 2). A partir de la información recopilada, se identificaron dos elementos fundamentales: 1) las relaciones de poder y 2) las identidades recreadas por los campesinos de Los Laureles. En este artículo se rescata la palabra de los pobladores hombres, mujeres, niños, niñas y jóvenes y se utiliza una clave para mantener el anonimato. 


\section{Las identidades y la construcción del territorio Los Laureles a partir de la búsqueda de tierras}

La población que habita en Los Laureles llegó a ese espacio buscando tierras. Al asentarse, conformó tres grupos definidos por su identidad. Para Chávez, "la identidad se centra en las formas en que el individuo, a través de las interacciones con los otros, asume su condición de miembro del grupo" (2003, p. 17). Es decir, "toda identidad [que] constituye un nosotros, tiene que construir de igual modo otro o alguien que no pertenece a la comunidad fundada" (Parra, 2015, p. 77). De acuerdo con Bolívar Echeverría, la identidad se construye a través de un proceso de familiaridad y de la cotidianidad del mundo en el que somos capaces de movernos cada uno y todos los días de la vida (citado en $\mathrm{Pa}$ rra, 2015, p. 78). Entonces,

construir identidad supone un proceso de construcción social de una realidad instituida a través de experiencias compartidas y prácticas que los sujetos realizan dentro de sus espacios de acción, de tal suerte que la pertenencia a un grupo [...] se conforma a partir de las "experiencias próximas" que, de manera espontánea y natural, viven y comparten las personas en el diario accionar de su existencia. La identidad se construye en razón del reconocimiento a la diferencia. Por otro lado, la identidad es un mecanismo de exclusión y de ejercicio de poder [...] conlleva la necesidad de la separación del nosotros de los otros con la consecuencia necesaria de una jerarquización y clasificación. (Chávez, 2003, p. 17)

En ese sentido, las identidades generadas en Los Laureles configuraron tres grupos sociales. El grupo I, integrado por 11 familias oriundas de las fincas La Cieneguita y La Esmeralda -que luego de la construcción de la presa Belisario Domínguez "La Angostura" (1976) emigraron a las fincas El Diamante y Ámbar y después se asentaron en el ejido Valle Morelos del municipio de Villacorzo-. Una vez en Valle Morelos, se dedicaron a trabajar como jornaleros, pues carecían de tierras. En 1986 decidieron migrar al ejido Tierra y Libertad, municipio de Villaflores, Chiapas. En 1987 se establecieron en las tierras que hoy son conocidas como Los Laureles.

El grupo II se compone de nueve familias que están subsumidas en una familia patrilineal. Son originarias de una finca ubicada en el municipio de Mapastepec, Chiapas. Los miembros de esta familia eran peones de rancho y se dedicaban a la ganadería; migraron en busca de tierras al ejido Valle Morelos, Villacorzo, y después, en 1989, a Los Laureles, por invitación del líder del Grupo I.

El grupo III está conformado por siete familias provenientes de comunidades ubicadas en los municipios de San Juan Chamula y de San Cristóbal de Las Casas, Chiapas, además del estado de Tabasco y de un rancho de Veracruz; en su mayoría son indígenas. Algunas familias de este grupo llegaron a Los Laureles en 1987; y otras, en 1992. El común denominador de todas estas 
familias es que llegaron a Los Laureles en busca de tierras para dedicarse a la agricultura.

Las poblaciones campesinas y los trámites agrarios

La historia de Los Laureles inicia cuando el grupo I y algunos integrantes del grupo III migraron al ejido Tierra y Libertad a finales de 1986, donde fueron recibidos por el comisariado ejidal. Pronto en asamblea, los ejidatarios de dicho lugar acordaron apoyarlos para que buscaran tierras donde asentarse. Así fue como los incitaron a migrar de nuevo, y en los primeros días del año 1987, tanto el grupo I como el resto llegaron a Los Laureles. El comisariado de Tierra y Libertad los apoyó realizando una solicitud ante la SRA para que esa institución reconociera las tierras como ampliación de Tierra y Libertad y de esta forma conseguir que el grupo I, por aquellos años conformado por seis familias, tuviera la legalidad de las tierras; sin embargo, la solicitud no procedió. Ante la negativa, el comisariado de Tierra y Libertad se deslindó del grupo y los animó a tramitar las tierras como un Nuevo Centro de Población Ejidal. Cabe señalar que ya contaban con el primer requisito - la posesión de las tierras - indispensable para iniciar los trámites agrarios.

Una vez asentados los campesinos en Los Laureles, ellos iniciaron el proceso para el trámite agrario en 1987 y no fue sino hasta el 10 de abril de 1995, a través de la Dirección General de Procedimientos Agrarios, Dirección de Nuevos Centros de Población Ejidal, que la SRA emitió el Acuerdo de Improcedencia, "en virtud de que el grupo gestor no agotó los procedimientos a que hace referencia el artículo 244 de la Ley Federal de Reforma Agraria” (SRA, 1995, expediente Núm. 425637). Dicho artículo señala que "procederá la creación de un nuevo centro de población, cuando las necesidades del grupo capacitado para constituirlo no puedan satisfacerse por los procedimientos de restitución, dotación o ampliación de ejidos, o de acomodo en otros ejidos" (DOF, 16 de abril de 1971, p. 518).

Al respecto, un miembro del comisariado señaló: “No sé por qué motivo el gobierno federal o estatal no han querido darnos la resolución de la legalización" (entrevista, 2010). En lugar de apelar la decisión de la SRA, los tres grupos acordaron comprar dos escrituras públicas (número 134 del Registro Público de la Propiedad del distrito judicial de Villaflores) que datan de 1967 y con la que acreditan la fracción El Arroyo Frío, ubicada en Villaflores, con una superficie de 4806 ha, y otra del mismo año que certifica la fracción El Encanto, con una extensión de poco más de 508 ha. Una vez que adquirieron las escrituras, los tres grupos acordaron conferirle el cargo de apoderado legal (AL) a un miembro del grupo II, por lo que acudieron al notario para registrar esta decisión, la que quedó respaldada jurídicamente en el documento expedido por la Notaría 76 del estado de Chiapas, escritura número cuatrocientos sesenta y ocho, volumen doce, expedido en la ciudad de Tuxtla Gutiérrez, Chiapas, México, el día trece de agosto de 1996, donde consta que: 
el poder general para pleitos y cobranzas, actos de administración y de riguroso dominio que otorga el señor José, a favor del señor Alejo [Apoderado Legal], acto que se consigna en los términos siguientes: Cláusula Primera el Sr. JLSG, con el expreso consentimiento de su esposa la señora Carmen, por medio del presente instrumento, confieren poder general para pleitos y cobranzas, actos de administración y dominio, en favor del Señor Alejo, en términos del artículo 2528 del código civil vigente en el Estado de Chiapas [...] para que en el ejercicio de este mandato lo representa ante toda clase de autoridades, tanto del fuero común como del fuero federal, ante tribunales fiscales, civiles, administrativas, penales y cualquier otro ramo; así como ante toda clase de personas físicas y morales, para que formule demandas o querellas, así como para que se desista de estas [...]. Cláusula segunda: El presente mandato se limita única y exclusivamente en lo que respecta al predio rústico denominado "El Encanto"; ubicado en el municipio de Villaflores, Chiapas, con una superficie de 508 hectáreas, veinticinco áreas [...]

Así el apoderado legal obtuvo las escrituras para representar a los tres grupos. Luego abandonaron los trámites ante las instancias agrarias y se limitaron a pedir constancias de posesión ante el Ayuntamiento Municipal de Villaflores cuando lo requerían, en general, para solicitar proyectos productivos. Solicitaron así once constancias de posesión durante el periodo analizado (véase figura 2). Los campesinos de Los Laureles optaron por esa opción debido a que su capacidad de agencia es limitada. La mayoría no sabe leer ni escribir y sus formas de lidiar con la vida se caracterizan por hacerlo a través de una red familiar y por la búsqueda de opciones promovidas por los "expertos" que los suelen orientar para intentar "resolver problemas dentro de los límites de información, incertidumbre y otras restricciones a las que los campesinos se enfrentan comúnmente. La capacidad de actuar y la capacidad de saber son dos rasgos característicos de la capacidad de agencia" (Long, 2007, p. 48).

En 2001 los pobladores solicitaron otra vez la resolución agraria ante la SRA debido a la presión que sintieron al entrar en vigor el decreto de la REBISE, que de inmediato los catalogó de "irregulares" pues no lograron demostrar la legalidad de su posesión agraria. En esta ocasión, la SRA señaló la procedencia de la posesión “de la presunta propiedad nacional denominada Los Laureles”, y con fecha 13 de marzo de 2002 se publicó en Tuxtla Gutiérrez, Chiapas, el aviso de deslinde, promovido por el comisariado. El perito realizó el deslinde de 900 ha; sin embargo, las autoridades ambientales aprovecharon la ocasión para modificar la línea colindante con la Zona Núcleo Tres Picos:

Nosotros fuimos con don Ernesto a las oficinas. Fuimos a levantar unas minutas de trabajo donde íbamos a respetar las líneas. Nosotros respetamos donde el ingeniero hizo su trabajo. Mandamos las notificaciones a los comisariados ejidales para hacer la nueva medición. Cuando comenzamos, iniciamos con 900 hectáreas, pero ahorita, como ya recortó la línea roja la biosfera, que es intocable, que es la montaña, pues ya quedó como 827 hectáreas. No son muchas hectáreas de montaña, lo que hay más son montes bajos para trabajar, ya la montaña ahí está. (MPE, 2010) 


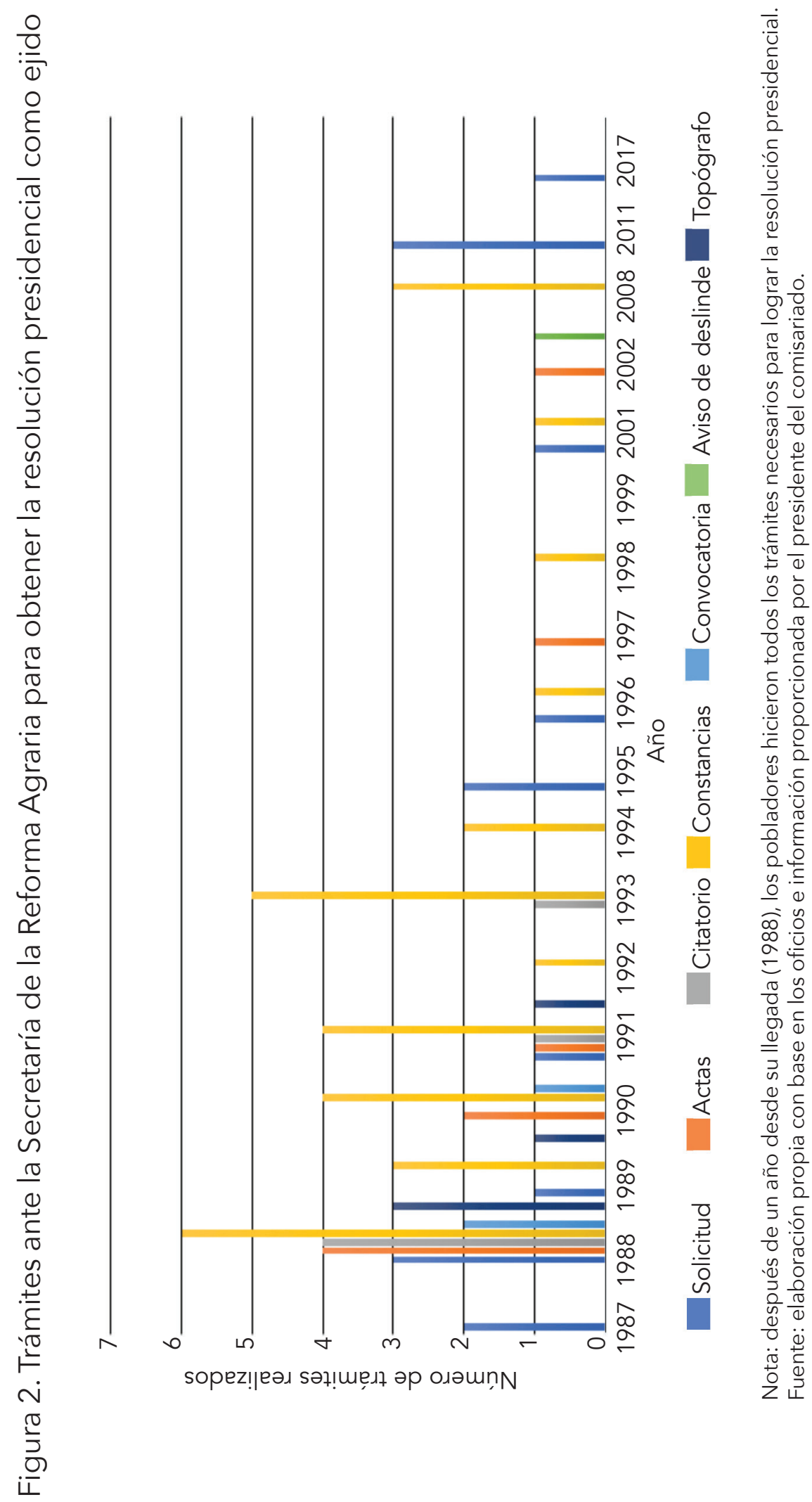


Fue fácil llegar a acuerdos, pues tanto don Ernesto† como el presidente del comisariado querían permanecer en su territorio. Por eso no dijeron que diez campesinos trabajaban las tierras que la CONANP quería recuperar para la conservación de la zona núcleo. Esos campesinos se quedaron sin tierra cuando se estableció el acuerdo.

Esa actitud revela la tendencia hacia la obediencia, tal como lo hacían cuando eran peones y recibían órdenes del patrón. Ahora, en sus tierras, el patrón era la Dirección de la REBISE y no consideraban otras opciones, pues "desde que la reserva se estableció, la gente se ha comprometido a respetar los términos de la reserva" (CMF, 2016). Un habitante de la comunidad percibe que:

En la historia de Los Laureles hay pocas fuentes de trabajo. La gente siempre va a los ejidos para buscar y tener un ingreso económico. Prácticamente todo lo que se cultiva o lo que se tiene aquí es para autoconsumo y no para comerciar, porque no da para más. (CMF, 2016)

La tierra representa un medio para la vida y para la configuración territorial; sin embargo, de manera paradójica, las unidades de producción familiar requieren al menos 6000 pesos para invertir en insumos y semillas. En los asentamientos constituidos de forma legal, es decir, regulares, los productores resuelven esta situación mediante los programas y los proyectos gubernamentales. No obstante, los campesinos de Los Laureles no pueden tener acceso a estos proyectos debido a que están en un asentamiento irregular, porque no han podido comprobar la posesión legal de la tierra, que es uno de los requisitos para solicitar esa ayuda. Aunada a esta problemática, los campesinos tienen que cumplir con los compromisos establecidos con la REBISE, como no desmontar más superficie para hacer cultivos, no quemar, talar ni cazar.

Identidades a partir de las actividades primarias

Los pobladores de Los Laureles, desde muy temprana edad, se han asumido como peones, sobre todo aquellos que nacieron, vivieron y trabajaron en una finca (historias de vida, 2016). La finca era la propiedad agraria de una persona o familia dedicada por lo general a la ganadería y al cultivo de maíz y de frijol (Toledo, 2002). Los dueños, patrones o rancheros contrataban a los campesinos para realizar diversas labores. Había personas que se especializaban en alguna actividad, como los vaqueros, encargados de la ganadería, y el peón de finca, dedicado a realizar actividades agrícolas, como sembrar maíz, frijol, arroz y cacahuate (Cruz-Morales, 2014a; historias de vida, 2017).

A las familias campesinas del grupo I que vivían dentro del perímetro de la finca se les conocía como baldíos y así se autonombraban. Ellos hacían tratos con el patrón para construir una pequeña choza y cultivar un pedazo de tierra a cambio de un pago que a menudo era en especie -maíz o frijol-. A través de este contrato surge la identidad de baldío (Cruz-Morales, 2014b; historias de vida, 2017). 
Tanto la identidad de peón como la de baldío nacen y se resignifican dentro de la finca. Pero cuando las familias campesinas de los grupos I y II emigran a Villaflores, continúan actuando y asumiéndose como peones frente a los ejidatarios de Tierra y Libertad y de Los Ángeles -ejido vecino-, en parte porque no tenían asegurada su estancia puesto que llegaron a un ejido ya legalizado sin posibilidades de incrementar el número de derecheros. ${ }^{2}$ Los recién llegados estaban a la expectativa y se pusieron a las órdenes de sus anfitriones en Tierra y Libertad, e incluso al llegar a las tierras de Los Laureles siguieron reproduciendo su identidad de peones, realizando actividades agrícolas bajo las órdenes de los ejidatarios de Tierra y Libertad. El grupo III asumió una identidad de peón y se asimiló a la cultura del grupo I. Hasta la fecha sus miembros continúan trabajando como peones de los ejidatarios (historias de vida, 2016).

En general, los campesinos de Los Laureles cambiaron sus formas de relacionarse a través del ejercicio de poder. Primero encontraron en el comisariado ejidal de Tierra y Libertad un respaldo que los cobijó y apoyó al realizar la solicitud del predio como primera ampliación del ejido. Después, y sin la intervención de un agente externo, el grupo I conformó un comité ejecutivo y cooperaron con dinero para realizar las gestiones agrarias, pero los reportes del comité ejecutivo fueron dudosos puesto que en numerosas ocasiones dijeron que los habían asaltado y eso generó desconfianza entre los miembros del grupo I. A pesar de que se sabían engañados, no tuvieron la capacidad de agencia para frenar las actitudes del comité ejecutivo y defender lo que era suyo; por el contrario, se portaron sumisos ante la situación.

Más tarde, la negativa de la SRA los obligó a buscar un nuevo agente que los orientara. Así, el grupo II se perfiló para ser el nuevo patrón. Uno de sus miembros propuso comprar escrituras apócrifas -50 pesos por hectárea- y consiguió que los grupos I y III confiaran en él para obtener el poder legal en las escrituras. Este proceso es de suma importancia debido a que esta compra permitió a los tres grupos estar dentro del Programa de Apoyos Directos al Campo (PRO$\mathrm{CAMPO}^{3}$ ) con el que inscribieron 178 hectáreas, acción que les permitió una mejora en los sistemas productivos y en sus viviendas. No obstante, al mismo tiempo estaban recreando las relaciones de poder y de dominación basadas en la relación entre patrón y peón, pues el apoderado legal asumió el papel de patrón y exigía un pago anual argumentando que gracias a él habían obtenido los recursos económicos del PROCAMPO. Por lo menos durante nueve años las personas que vivían de forma permanente en la comunidad le pagaron $30 \%$ de lo que recibían del apoyo y los que vivían fuera de la localidad, 50\% (historias de

2 Localmente se le conoce como derecheros a las personas que están dentro de la carpeta básica (conjunto de documentos relacionados con la propiedad agraria: plano, padrón o censo de los beneficiarios, resolución presidencial, sentencia agraria, aviso de deslinde, entre otros), que tienen derecho a la tierra, que son fundadores del ejido y que están reconocidos por la ley.

3 El PROCAMPO se instrumenta a finales de 1993. Se diseña en vísperas de la apertura comercial del Tratado de Libre Comercio de América del Norte. El programa inició con el propósito de transferir apoyos económicos para compensar a los productores nacionales por los subsidios que reciben sus competidores extranjeros, en sustitución del esquema de precios de garantía de granos y oleaginosas. Su objetivo inicial fue apoyar a los productores de granos básicos para mejorar el nivel de ingreso de las familias rurales, sobre todo a aquellos productores que destinan su producción al autoconsumo (Congreso de la Unión, 2001). 
vida, 2016). No sólo el PROCAMPO sirvió para reproducir las relaciones de poder y dominio, también sucedió en otros pequeños proyectos y se recrudecieron esas relaciones cuando el apoderado legal los despojó de un crédito ganadero que habían obtenido (historias de vida, 2016).

Los grupos I y III no reclamaron ni exigieron sus derechos porque, a decir de los entrevistados, el AL realizaba las gestiones necesarias para que todos se beneficiaran en el caso de PROCAMPO. Aunque no querían dar el porcentaje de dinero que él pedía, no había oportunidad de negarse, pues él se los arrebataba, recalcando que tenía las escrituras. Es decir, las escrituras fueron el instrumento del ejercicio de poder, pero, a pesar de los conflictos suscitados entre los diferentes grupos, todos siguieron leales al apoderado y no fueron capaces de frenarlo; por el contrario, en algunas ocasiones lo defendieron y protegieron (historias de vida, 2016).

En términos de la identidad productiva, al tener acceso a los recursos del PROCAMPO, los tres grupos se reconocieron como maiceros. Abrían y quemaban superficies para la siembra del maíz, cosechaban para el autoconsumo y el mercado - vendían cierto porcentaje de su producción al Grupo Industrial Maseca, S. A.- . Cuando las reglas de operación del PROCAMPO cambiaron, ya no fue suficiente registrar las 178 hectáreas a nombre del AL. Las nuevas reglas exigían comprobar la legal posesión de las tierras y presentar los certificados agrarios, no sólo la constancia de posesión, como habían venido haciendo. Además, las reglas señalaban que un apoderado legal no podía cobrar más de 100 hectáreas. En 2009, dado que no pudieron comprobar la legal posesión de las tierras, dejaron de recibir el apoyo del PROCAMPO. Los entrevistados aseguran que el AL tramitó unas escrituras privadas para cobrar las 100 hectáreas reglamentarias del PROCAMPO; sin embargo, un líder político de la Región Frailesca, que conocía los antecedentes del apoderado legal, intervino para que no pudiera beneficiarse con dicho programa. Estos acontecimientos exacerbaron los conflictos y la desconfianza, empero los integrantes de los grupos I y III seguían necesitando la capacidad de agencia del grupo II y han recurrido a él en diversas ocasiones para gestionar proyectos, como, por ejemplo, un proyecto con la empresa Cafés California para renovar sus plantaciones de café (entrevistas, 2010; historias de vida, 2016).

Por otro lado, la ganadería es un proyecto del gobierno de Chiapas implementado desde 1932 (Fernández y Tarrío, 1983). La actividad ganadera ha desempeñado un papel importante en la configuración territorial. En 1999 el banco Bancrisa otorgó a los tres grupos, después de las gestiones apoyadas por la comunidad, un crédito ganadero para comprar 2 sementales y 40 vacas vientres. Con ese ganado se identificaron como ganaderos por un tiempo breve. Realizaron pequeñas inversiones para acondicionar los espacios donde tendrían a los animales, pero de nuevo el grupo II fue el único beneficiado (13\% de los productores), dado que el AL se apropió del proyecto y no hizo el reparto como habían acordado.

En la actualidad 10 familias siguen teniendo ganado, y de 2009 a 2015 formaron parte de la Escuela Campesina de Ganadería, organizada por la Dirección de la REBISE. Ahí, de manera incipiente, experimentaron la producción de ga- 
nado bajo sistemas silvopastoriles (esquema que combina pasto, árboles y otras plantas forrajeras). Las familias de Los Laureles practican formas tradicionales de manejo ganadero, como el sistema de ganadería a medias o al partir, ${ }^{4}$ ganadería extensiva y la renta de potreros con ganaderos de otros ejidos de la CART. En general, la identidad ganadera (véase figura 3) es exigua en la localidad y al mismo tiempo forma parte del imaginario colectivo que está presente como una aspiración económica, dado que tener ganado representa un seguro de vida en casos de emergencia, a menudo para resolver problemas de salud.

A partir de la actividad ganadera los conflictos también fueron un factor importante en la vida de las familias de Los Laureles. Después de haber conseguido el ganado, el grupo II se quedó con los dos hatos. De hecho, un miembro del grupo I decidió irse del pueblo para evitar un enfrentamiento armado, mientras que los demás guardaron con celo su enojo, al tiempo que continuaron construyendo su territorio (historias de vida, 2016).

Para implementar la Escuela de Campo sobre ganadería, la Dirección de la REBISE solicitó a la asamblea general que nombrara a un representante cuya función sería promover conocimientos sobre la ganadería amigable con el ambiente. Para ello, el promotor tenía que asistir a los cursos y replicar los talleres prácticos en el grupo comunitario. Así, por más de tres años, el promotor electo, que pertenece al grupo III, llevó a cabo las actividades encomendadas. El grupo II estuvo en desacuerdo desde el nombramiento. Entonces algunos de sus miembros se dirigieron al técnico responsable del proyecto en la CONANP y señalaron que el promotor no llevaba a cabo las actividades. En respuesta, la CONANP consideró conveniente nombrar promotor a un miembro del grupo II quien, luego de que advirtiera que la Escuela de Campo no ofrecía salario ni compensación alguna, dejó de asistir a los cursos, de modo que se rompió la dinámica que se había establecido con el primer promotor (CES, 2016).

Identidades emergentes a partir del decreto de la REBISE

La entrada en vigor de la REBISE tuvo efectos importantes en las identidades de los pobladores de Los Laureles. Primero fueron considerados una población irregular porque no contaban con documentos que acreditaran la legal posesión de las tierras. En segundo lugar, se convirtieron en custodios de la naturaleza bajo conservación, ya que para permanecer en las tierras que ocuparon con anterioridad al decreto de la reserva, tuvieron que firmar minutas de acuerdos y asumir algunos compromisos, como 1) conservar las áreas colindantes con la Zona Núcleo Tres Picos, 2) realizar actividades agrícolas sin afectar las áreas

4 La ganadería a medias o al partir "es un convenio difundido en la región, que se entabla oralmente, sin documentos escritos y sin un compromiso temporal definido. El trato se establece entre un ganadero, originario de otros lugares de la región, y un campesino o ejidatario local que posee la cantidad de tierra suficiente para la pastura de ganado. El primero aporta capital circulante en la forma de pie de cría, mientras que el segundo lo hace con tierra, trabajo e insumos, como semilla para pasto, fertilizantes, vitaminas y medicamentos que casi siempre son aportados por él en su totalidad, aunque se pueda llegar a algún acuerdo al respecto con el dueño. Para campesino o ejidatario, el beneficio que obtiene del convenio se concreta en especie: para él son la mitad de las crías y la leche de las vacas que han parido" (Flores, 2013, p. 211). 


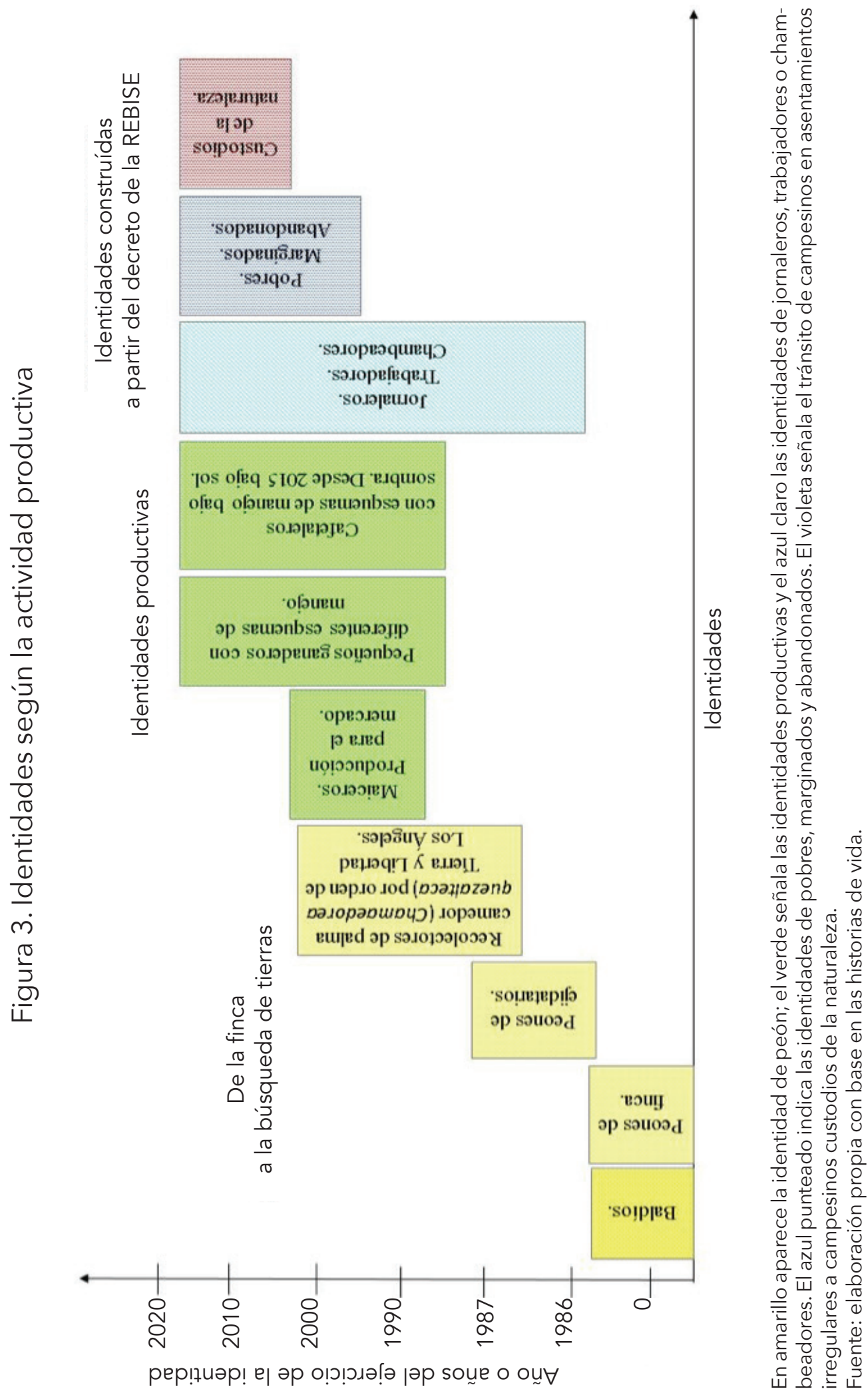


en conservación estricta, 3) frenar la frontera agropecuaria, 4) no quemar, 5) en caso de incendios, evitar la propagación del fuego y 6) no cazar animales silvestres (historias de vida, 2010 y 2016).

Con el decreto de reserva, la identidad de peones se fortaleció, pues tuvieron que aceptar ser custodios de la naturaleza. Al paso del tiempo emergió un nuevo "patrón", la CONANP, con órdenes suficientes para los tres grupos. Un integrante del grupo I da un ejemplo del poder que se ejerce a través de la conservación. En el contexto del huracán Stan (2005), fenómeno natural que derribo árboles y dejó madera muerta en las tierras de Los Laureles, relata:

Hicimos una solicitud para [extraer] la madera muerta. En ese tiempo había mucha madera de ocote seco. Lo queríamos sacar, pero como estaba delicado [penado] [...] queríamos sacar la madera en vez [de] que se perdiera. La queríamos hacer regla o morrillo o tablitas para que no se echara a perder. Nos agarran. Y viene [el] de la forestal a decirnos: "Saben qué, no estén tocando nada de aquí. Al que lo caigan, va ir a parar al bote [a la cárcel]". Bueno, de ahí se volvió a poner triste la gente. En vez de que se echara a perder, aunque sea algo se hubiese aprovechado. Pero ¡ni eso! Imagínese, en esta pobreza se necesita sacarlo, pero no dieron lugar. Como les dijimos que íbamos a sacar esa madera, del diario estaban aquí [las autoridades ambientales]. (MPJ, 2010)

En la narrativa anterior se destaca la vigilancia que viven durante ciertos periodos los habitantes cercanos a la zona núcleo. Por otra parte, con la autopercepción que tienen los campesinos de Los Laureles sobre su situación económica, recrean su identidad de pobres y marginados, sobre todo por no lograr el acceso a los proyectos gubernamentales, como lo hacen los campesinos de otros ejidos. Ante esta situación, terminan acatando las órdenes del nuevo patrón, representado por las autoridades de conservación. En la búsqueda de mantener la zona de amortiguamiento, las autoridades ambientales se valen de la vigilancia, como la observación de las prácticas humanas por satélite, y de narrativas. Los tres grupos aseguran que los vigilan día y noche por medio del satélite. El argumento de las autoridades ambientales es que mediante esa observación pueden conocer el grado y el avance de la deforestación.

Otro componente grave para los tres grupos, pero más para los grupos I y III, es asumir la identidad de pobres, marginados y olvidados que ha debilitado aún más su capacidad de agencia.

Yo sé que mi comunidad [tiene] las ganas de trabajar [...]. Lo que no tenemos son los medios. Un medio donde quizás también [...] alguien [nos] mueva. Yo sé que en las diferentes dependencias de gobierno hay recursos, pero nosotros [...] carecemos de ese conocimiento [sobre] gestorías, pues allá se quedan. Como le digo, los apoyos de café [...] sabemos desde qué tiempo están entregando apoyos el gobierno, pero aquí nunca llegan. Se quedan allá a donde están los que tienen. Aquí, donde estamos nosotros, es muy difícil. Tenemos que sobrevivir con el trabajo de nosotros mismos. (MPE, 2016) 
La identidad de jornaleros, trabajadores y chambeadores siempre la han tenido, dice MLP, perteneciente al grupo I (2016): “Ganando nos mantenían”. Por su parte, CHJ, también del grupo I, comparte: "Yo trabajaba. Yo salía a vender pan. Ganaba yo por hacer tortillas y salía a trabajar al monte. También llevaba costales de maíz, fertilizante. Acarreaba agua para fumigar”. (2016). LCE, del grupo II, recuerda: “Llenábamos los tanques de agua para el ganado. Trabajamos con el ganado. Ahí aprendimos a hacer el queso de sal” (2016). Otra persona del grupo III señala: "Salíamos a trabajar, cortábamos palma [...]. Cada sábado lo íbamos a entregar para que hubiera dinero para el gasto y cuando había corte de café [...] íbamos a trabajar para ganar para que haya comida para la familia" (HHJ, 2016).

El pasado de chambeadores, trabajadores y peones, y siempre a las órdenes de un patrón, es una historia que no se diferencia de la más reciente. Así lo asegura LCE, integrante del grupo III, quien comenta:

[Aquí] no hay trabajo. Bueno, trabajo hay, pero quien pague no hay. Eso es que nos aburrimos, pues, porque allá semanal iba a ganar o allá donde estábamos [mi esposo] vendía su pescado y ya había [dinero]. Pero aquí, ése es el problema que no hay. Salen los pobres a ganar, a veces se van lejos porque saben que no hay, pues. Mi hijo, que vivía en la esquina, se fue para Toluca con su mujer. Como no hay trabajo, a veces siembran frijolito, su maicito. Hay veces que se da; hay veces que no. Mi [otro hijo] que estaba en Los Ángeles, igual se fue para los Estados. Ahí dejó solita a su familia. (2016)

MPC, que pertenece al grupo II, comparte:

Hasta ahorita me dicen mis hijos que es un lugar muy pobre, que no hay trabajo, que no hay nada. Me dicen mis hijos: "Vámonos ya, más para allá abajo. Aquí no hay trabajo". Pero no. Yo no me quiero ir, pues ya estoy bien hallada. El problema en estas tierras es que no hay trabajo [...]. Que haya trabajo para que los hombres trabajen, chambeen [...] para el pan de cada día. (2016)

Para las familias de Los Laureles la solución es el trabajo, pues es lo que les permite sobrevivir, pero éste es intermitente y dispar; algunos pueden invertir en la producción del campo mientras que otros no. Por otro lado, su poca capacidad de agencia no les permite el acceso a los insumos necesarios para la producción; además, al no contar con la legalidad de sus tierras, se ven limitados para gestionar apoyos de mayor envergadura ante instancias municipales o no gubernamentales. No tienen otra opción más que ser jornaleros y custodios sin sueldo de la conservación, en espera de que las autoridades ambientales les retribuyan con pequeños proyectos a cambio; pero la CONANP tampoco puede generar estrategias de apoyo debido a los conflictos intraterritoriales en los que se ven inmersos los tres grupos. 
Las historias de vida muestran que, desde su niñez, los ahora adultos habitantes de Los Laureles han estado en constante estrés familiar y económico. En su mayoría son huérfanos y han trabajado con sus familiares a cambio de vestido, alimentos y en algunos casos de una remuneración económica. Desde infantes asumieron responsabilidades en el trabajo doméstico, en el trabajo remunerado vendiendo algún producto y, en algunos casos, en ambos (véase figura 4). Al quedar huérfanos, su madre o su padre se volvieron a casar y estuvieron a la orden de algún familiar (tío o tía, según el caso). ${ }^{5} \mathrm{Ni}$ los hombres ni las mujeres concluyeron su educación primaria.

Figura 4. Porcentaje de orfandad, trabajo remunerado y responsabilidad en el trabajo doméstico y de mercado

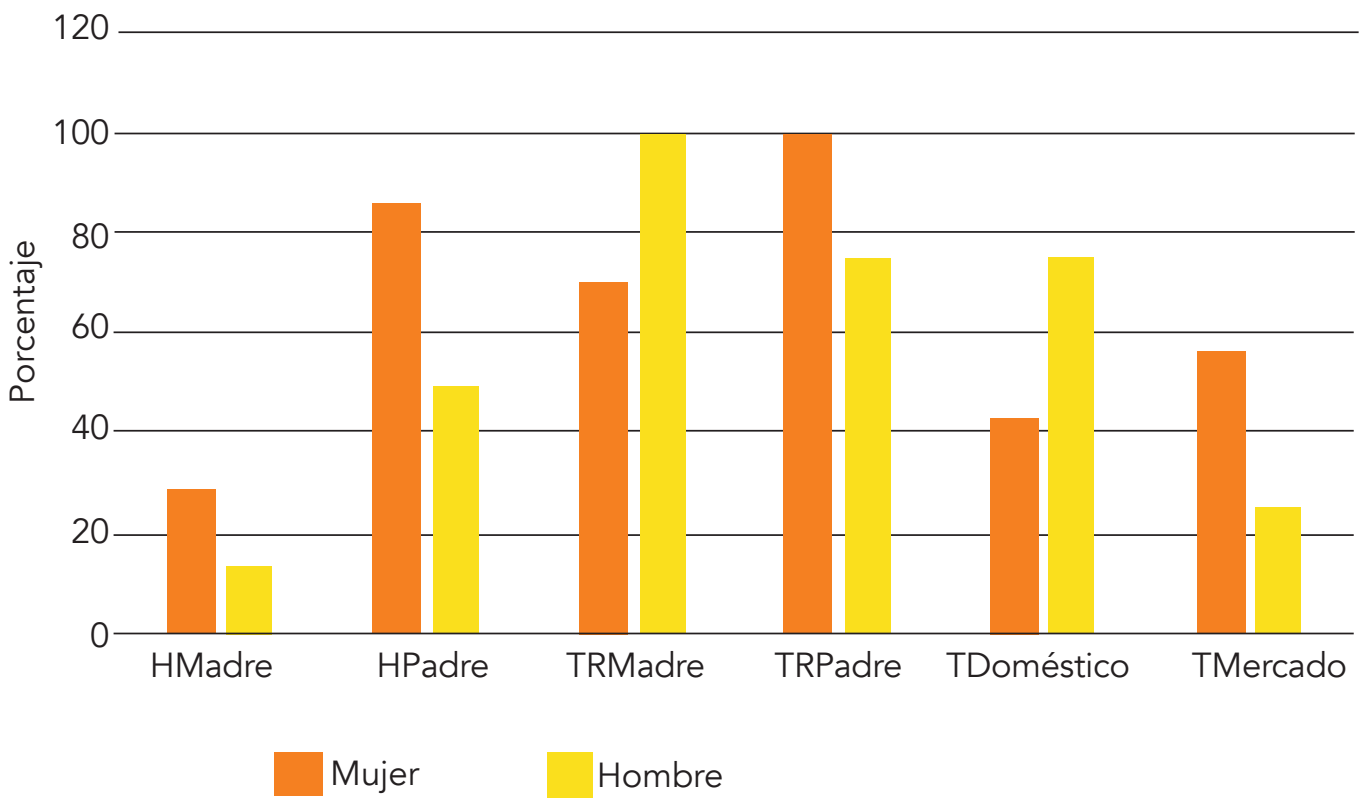

HMadre=Huérfano de madre, HPadre=Huérfano de Padre, TRMadre=Trabajo remunerado de la Madre, TRPadre=Trabajo remunerado del Padre, TDoméstico=responsabilidad en el trabajo doméstico, TMercado=responsabilidad en el trabajo del mercado.

La figura demuestra que los porcentajes más altos son para las mujeres, excepto en el trabajo remunerado por la madre y en el trabajo doméstico, en el que los porcentajes son mayores para los hombres. El porcentaje de orfandad es más elevado para las mujeres. Lo más probable es que por eso los datos demuestran un porcentaje mayor para las mujeres del trabajo remunerado por el padre (padrastro) y un porcentaje mayor en el trabajo de las mujeres en el mercado. En el medio rural es costumbre mandar a las niñas a vender los productos que elabora la madre, como pan, dulces, tortillas o frutos que se recolectan.

Fuente: elaboración propia con base en las historias de vida.

5 En la localidad se le nombra tío al padrastro, o tía a la madrastra. 


\section{Discusión}

Después de treinta años de haberse posesionado de las tierras, los miembros de los tres grupos no han obtenido la resolución presidencial para formalizar la legal posesión agraria, debido a que su pasado como peones y trabajadores agrícolas a las órdenes y bajo el yugo de un patrón o finquero les impide incentivar su capacidad de agencia para iniciar un proyecto colectivo y concluirlo. Por lo tanto, se asumen como una comunidad marginal y reproducen su identidad de peones para ganarse la vida trabajando a la orden de un patrón, a pesar de poseer una considerable cantidad de tierras en las que, si tuvieran los recursos necesarios, podrían sembrar diversos cultivos o criar animales.

Es decir, "la propiedad, como institución y proceso social complejo, hace visibles las prácticas sociales de apropiación y la percepción que tienen los agentes locales involucrados en este proceso" (Mora, 2013, p. 48). Al no contar con este disfrute o beneficio, los campesinos van forjando identidades con base en las relaciones de poder que los subsumen y a su vez los reprimen y los limitan. Por otro lado, a raíz del decreto de ANP, experimentan prohibiciones en sus prácticas de apropiación, como no desmontar más superficie para hacer cultivos, no quemar, talar ni cazar. Además, al no recibir apoyos para los proyectos productivos por su situación de irregularidad agraria, exacerbada a partir del decreto de la REBISE, se ven en la necesidad de buscar trabajo en los ejidos vecinos, y algunos buscan empleo en los estados del norte de México y en Estados Unidos.

Su historia de vida reveló que los campesinos de Los Laureles se identifican como peones, trabajadores y chambeadores. Hay campesinos que, aunque cuentan con una considerable cantidad de tierra no la sienten como suya y señalan: "Nosotros somos trabajadores, chambeadores. Somos pobres" (entrevistas personales e historias de vida, 2010; 2017). Es decir, se asumen como pobres, peones o jornaleros frente a los ejidatarios que sí lograron obtener la resolución presidencial de posesión y que pueden beneficiarse con el apoyo de diversos proyectos gubernamentales.

Los miembros de los grupos I, II y III han construido su identidad a partir de dar sentido a las actividades productivas que realizan, pero sobre todo su identidad más simbólica es asumirse como pobres, quizá porque esa identidad se construyó a partir de la institución que resultó ser más determinante: la finca, aunque también reconocen otras identidades. Al respecto, Castells señala: "las identidades [que] pueden originarse en las instituciones dominantes, sólo se convierten en tales si los actores sociales las interiorizan y construyen su sentido en torno a esta interiorización" (2009, p. 29). Para un individuo o un actor colectivo puede haber una pluralidad de identidades; no obstante, "tal pluralidad es una fuente de tensión y contradicción tanto en la representación de uno mismo como en la acción social" (Castells, 2009, p. 28).

Los campesinos de Los Laureles tienen una capacidad de agencia muy poco desarrollada, además tienen pocas habilidades para insertarse en una estructura social. En este sentido, la teoría de las necesidades de Max-Neef, Elizalde y Hopenhayn (1986, p. 25) apunta a que "la calidad de vida dependerá 
de las posibilidades que tengan las personas de satisfacer adecuadamente sus necesidades humanas fundamentales". Es importante tener en cuenta que las necesidades humanas según esta teoría son "las necesidades de subsistencia, protección, afecto, entendimiento, participación, ocio, creación, identidad y libertad" (Max-Neef et al., 1986, p. 26). Es evidente que los campesinos del estudio de caso no tienen cubiertas estas necesidades fundamentales debido a que en su vida cotidiana persiste la inseguridad agraria, en su territorio prevalece el conflicto y siempre están reinventando su identidad para subsistir. Los campesinos experimentan falta de libertad cuando se sienten observados por la comisión y cuando no pueden tomar decisiones, como en el caso de la madera muerta. Por otra parte, la capacidad de agencia es marginal cuando no ejercen "los niveles y ámbitos de participación y debate público: en la lucha por los derechos individuales, sociales, y comunitarios; en la expresión pública argumentada de sus ideas, creencias y preferencias [...] y en la definición de los principios constitucionales" (García-Barrios, 2008, p. 50). Amartya Sen (2000) argumenta que la capacidad de agencia es la libertad individual que un agente o actor posee para elegir, expresar, decidir, contar con servicios económicos, tener oportunidades sociales, garantías de transparencia y seguridad protectora. Es decir, la capacidad de agencia es un concepto que señala las relaciones del individuo con su entorno social, político y económico, y también cómo tiene que disponer de todos sus acervos para mantenerse dentro de una estructura social.

Las relaciones de los individuos de los grupos sociales de Los Laureles se limitan al entorno local próximo; por ello, la población de Los Laureles es una comunidad marginal dado que se caracteriza por estar organizada alrededor de la familia patrilineal y de las relaciones de vecindad organizadas a partir de la conformación de grupos en los que la identidad está muy marcada por su origen natal -ser hijo de peón-y lugar de procedencia - la finca-. En ese sentido, los marginados "buscan de manera discontinua y siempre a corto plazo recursos económicos" (Touraine, 1987, p. 65). Entonces, debido a esto, asumen una identidad de jornaleros o chambeadores y buscan a quién entregarle cuentas y por ende a quien pague por su trabajo. Les es difícil emprender una iniciativa por sí solos, lo que es una conducta típica de las comunidades marginales; sin embargo, mantienen una capacidad defensiva. Al respecto, Touraine señala que "estas comunidades tienen grandes dificultades para intervenir en la vida pública y necesitan la intervención de caciques, jefes políticos o religiosos, para relacionarse con las instituciones y los centros de decisión" (1987, p. 65).

Esta situación es visible en la historia de la población de Los Laureles, que en un principio dependió del comisariado del ejido Tierra y Libertad y después de un apoderado legal nombrado por los mismos pobladores y a quien, al cederle el poder, convirtieron en su verdugo. Más tarde, con la entrada en vigor de la REBISE, encuentran en esa institución un nuevo actor que ejerce poder sobre ellos, representación que los conduce a la obediencia y a aceptar la imposición de reglas y normas influenciadas por organismos internacionales.

En términos de representación, la comunidad se encuentra en desventaja, pues sólo ha tenido tres comisariados en treinta años de historia, lo que repre- 
senta un detrimento, como se ilustró en un conflicto surgido frente a la comunidad vecina de El Triunfo, pues tuvieron que solicitar apoyo a las autoridades municipales para que intervinieran y se solucionara el conflicto. En el caso del PROCAMPO, acudieron al líder regional Germán Jiménez Gómez ${ }^{6}$ para que los ayudara a evitar que el apoderado legal continuara beneficiándose, al cobrarles un porcentaje de sus apoyos. En síntesis, la comunidad ha necesitado la intervención de otras personas para enfrentar sus adversidades y continuar con la construcción de su territorio, ya que no logra emerger alguien que pueda asumir el rol de líder, alguien en quien ellos puedan confiar y estar seguros de que no los defraudará. Esas prácticas de dependencia se han mantenido presentes durante su vida y las continúan reproduciendo día a día. De este modo conforman sus identidades, su cultura e ideología (Aguado y Portal, 1991).

Además, el hecho de asumirse como una comunidad marginal los ha limitado en la gestión para legalizar sus tierras y para tener acceso a los beneficios de los proyectos gubernamentales, ya que en México demostrar la legalidad de tierras es un requisito indispensable de las políticas públicas. En ese tenor, Mora señala que "la posesión de un título es una condición indispensable para el crecimiento y la expansión económica, es un activo, un símbolo de riqueza, de seguridad y poder" (2013, p. 48). Un título de propiedad es también una condición para forjar la identidad de un grupo de personas, pues al no tener certeza agraria pueden ser vistos (por los otros) como marginales, pobres y segregados (Camacho-Bernal y Trench, 2019).

La carencia de un título de propiedad significa permanecer al margen de posibles beneficios económicos para trabajar las tierras. Por eso se movilizan para trabajar, recreando su identidad de jornaleros, peones o chambeadores y aceptando las relaciones de poder. Como señala Kourí:

En un clima de persistente pobreza rural e inseguridad alimenticia, en un país profundamente marcado por la incesante migración [...], la reforma agraria es ampliamente considerada, si no un fracaso, sí un malogro en términos económicos, pues resultó incapaz de generar una agricultura próspera que elevase el nivel de vida de la mayoría de la población rural. (2010, p.14062)

La limitada capacidad de agencia que poseen los pobladores de Los Laureles no se debe sólo a una condición aislada e individual, es una causa estructural de México. En Chiapas esta situación es más evidente. El reparto agrario fue tardío y duró más de siete décadas, debido al triunfo de la llamada revolución mapache o mapachista (Alejos, 2004; González-Esponda, 2015; Zebadúa, 2011) que aún no termina. En Chiapas hay cerca de 432600 hectáreas de tierra sin resolución agraria en las que viven cientos de familias campesinas en condiciones similares a las de Los Laureles e incluso peores, como las catalogadas por las leyes mexicanas como “nacionaleros” (Procuraduría Agraria y Secretaría de Desarrollo Agrario, Territorial y Urbano [SEDATU], 2014). La mayoría de los

6 Germán Jiménez Gómez es líder político partidista de la región económica La Frailesca. Ha sido dos veces presidente municipal de Villaflores (1980-1982 y 2011-2012). 
nacionaleros han estado aislados y algunos no han tenido la oportunidad de alfabetizarse. Esta condición tiene gran influencia en la construcción de los territorios, ya que al necesitar de un apoderado o de otra persona que tenga más capacidad de agencia son proclives al conflicto, a la desconfianza y a las relaciones de poder y sometimiento. Es decir, se cumple con la frase "somos en razón de nuestra historia" (Aguado y Portal, 1991), esa historia que marca y distingue, que hace que se construyan y reconstruyan múltiples identidades, ya sea en lo económico, lo productivo, lo étnico y a partir de diversas condiciones, como la autorresignificación de un actor frente al otro: uno que confiere, por ignorancia, miedo o poca capacidad de agencia el ejercicio del poder a otro, aunque el actor que confiere quede subyugado y desposeído de sus tierras, bienes y esperanzas.

Por otro lado, la finca ha tenido un papel determinante en la construcción de las identidades y del territorio no sólo en el mundo indígena, sino en general en el mundo rural mexicano (Aguado y Portal, 1991; Alejos, 2004; Uzeta, 2011). Así, la identidad aparece como respuesta emergente ante los cambios vertiginosos que vive el mundo rural; en primer lugar, a partir de la finca que determinó y forjó una identidad de peón; después, a raíz del Estado benefactor, que con sus políticas trató de dotar de patrimonios a los campesinos (ejidatarios, comuneros) y más tarde el neoliberalismo con su política ambiental subyugó a los peones liberados por el reparto agrario para poco a poco subsumirlos en un mundo donde el trabajo agrícola demanda de nuevo más peones.

En síntesis, las poblaciones que continúan reproduciendo una identidad basada en el sometimiento de uno frente al otro, con dificultad lograrán obtener la resolución agraria de posesión, debido a las condiciones en las que han vivido (exclusión y marginación), lo que refuerza la incapacidad de sostener emocional, económica y organizadamente un proceso tan largo como es la gestión agraria. El proceso de solicitud incluye diversos procedimientos, además de que demanda una constante atención para que los ingenieros encargados de la situación agraria puedan darle seguimiento. Es un gran problema, dado que una economía marginal no puede sostener dicho proceso. Por otra parte, la marginalidad permite la sostenibilidad de ejercicios de poder, por ejemplo, la corrupción, mediante la cual los pocos recursos económicos que un jornalero puede ganar en un día los consumen los "representantes", justificando el seguimiento del proceso.

Al interior del territorio el ejercicio del poder se traduce en constantes, complejos procesos y dinámicas de luchas por la posesión y control territorial que, a su vez, se convierten en apropiaciones, construcciones y trasformaciones territoriales. Alude, así mismo, a la exacerbación de un escenario basado en relaciones de dominio (Minda-Batallas, 2002).

Tal como señala Alejos (2004), las identidades son diversas y dependen de las interrelaciones entre las otredades concretas. Entonces, las territorialidades construidas por los tres grupos han sido el escenario de las relaciones sociales caracterizadas por las múltiples identidades y conflictos "ante el peso de la pobreza estructural histórica, que soportan” (Morales y Rivera, 2016, p. 52). En Los Laureles, las identidades se basan en la interacción de sus reproducciones 
socioeconómicas (maiceros, ganaderos, jornaleros) y en las emergentes (custodios de la naturaleza) al entrar en vigor la REBISE. Sin embargo, al no reforzar sus capacidades, sobre todo su capacidad de agencia, las interacciones frente a los otros actores favorecen la reproducción social de su identidad pasada, es decir, la de peones.

\section{Conclusiones}

El territorio de Los Laureles es el escenario donde a partir de las relaciones sociales se recrean las identidades campesinas (pasadas y emergentes). Es también el marco espacial donde se determina el dominio soberano del Estado a través de las políticas ambientales que impulsan la conservación de los territorios a costa del sometimiento de una población que tiene poca capacidad de agencia.

En ese sentido, la capacidad de agencia es determinante para que un pueblo obtenga la resolución agraria o sus títulos de propiedad y así logre mejores condiciones de subsistencia. Los Laureles es un pueblo que permanece en el limbo agrario, y que en medio de la inseguridad agraria y de la marginación, lucha constantemente para sobrevivir. El territorio, como espacio apropiado, permite reproducir las identidades individual y colectiva y, dependiendo de las dinámicas y actividades espaciales, refuerza o disminuye la capacidad de agencia de los actores; es por ello que las dinámicas de apropiación varían de una familia a otra y de un grupo a otro. Es decir, la construcción del territorio depende de las capacidades que cada uno tenga para crear, recrear y apropiarse del territorio. Por eso la apropiación también es diferenciada y desigual.

Aunque las dinámicas sociales son cambiantes, en el territorio los campesinos recrean las identidades dependiendo del origen de los pobladores, de sus actividades productivas y de las políticas de conservación. Al fortalecer su identidad y autopercepción como pobres y marginalizados, los pobladores reducen su capacidad de agencia y limitan los esfuerzos que hacen para superar la irregularidad agraria y las limitaciones que ella conlleva.

\section{Referencias}

Aguado, J. C., y Portal, M. A. (1991). Tiempo, espacio e identidad social. Alteridades, $1(2), 31-44$.

Alejos García, J. (2004). Identidad étnica y conflicto agrario en Chiapas. Amérique Latine Histoire et Mémoire. Les Cahiers ALHIM (10), 1-15 Recuperado de https: / / alhim.revues.org/114

Anaya, F. C., y Espírito-Santo, M. M. (2018). Protected areas and territorial exclusion of traditional communities: analyzing the social impacts of environmental compensation strategies in Brazil. Ecology and Society, 23(1), 8. doi: 10.5751/ES-09850-230108 
Camacho-Bernal, T., y Trench, T. (2019). De la "tierra para los pobres" a espacios de conservación y disputa: la Selva Lacandona y la Sierra Madre de Chiapas desde la perspectiva de la justicia ambiental. LiminaR. Estudios Sociales y Humanísticos, 17 (2), 48-66.

Castells, M. (2009). La era de la información. Economía, sociedad y cultura. El poder de la Identidad, vol. II. Madrid: Siglo XXI.

Chávez Arrellano, M. E. (2003). Identidad y cambios culturales. Los mazahuas de San Antonio Pueblo Nuevo. México: Universidad Autónoma Chapingo.

Cruz-Morales, J. (2014a). Construcción de territorios ambientales mediante procesos de aprendizaje social. El caso de la Cuenca Alta del Río El Tablón, Reserva de la Biosfera La Sepultura, Chiapas, México (tesis doctoral). Universidad Autónoma Metropolitana (UAM), México.

Cruz-Morales, J. (2014b). Desafíos para construir la democracia ambiental en la Cuenca Alta del Río El Tablón, Reserva de la Biosfera La Sepultura, Chiapas, México. En C. Legorreta Díaz, C. Márquez Rosano y T. Trench (coords.), Paradojas de las tierras protegidas en Chiapas: democracia y política ambiental en reservas de la biosfera en Chiapas (pp. 21-60). México: Universidad Nacional Autónoma de México (UNAM) y Universidad Autónoma Chapingo.

Cruz-Vargas, J. C. (5 de junio de 2017). En 10 años, 4.8\% de la propiedad ejidal y agraria del país pasó a manos privadas: INEGI. Proceso en Línea. Recuperado de https://www.proceso.com.mx/493792/en-10-anos-4-8-la-propiedadejidal-agraria-del-pais-paso-a-manos-privadas-inegi

Diario Oficial de la Federación (DOF). (16 de abril de 1971). Ley Federal de Reforma Agraria. Libro Primero, Reformas a la ley DOF/17/01/1984, pp. 518 Recuperado de http://www.pa.gob.mx/publica/MARCO\%20LEGAL\%20PDF/ LEY\%20FED\%20REF\%20AGR.pdf

Diario Oficial de la Federación (DOF). (13 de marzo de 2002). Aviso de deslinde del predio presunta propiedad nacional denominado Los Laureles, ubicado en el municipio de Villaflores, estado de Chiapas, México.

Diario Oficial de la Federación (DOF). (28 de noviembre de 2016). Ley General de Asentamientos Humanos, Ordenamiento Territorial y Desarrollo Urbano. Cámara de Diputados del H. Congreso de la Unión, Secretaría General, Secretaría de Servicios Parlamentarios. Nueva Ley. Recuperado de http:// www.diputados.gob.mx/LeyesBiblio/pdf/LGAHOTDU_281116.pdf

Fernández, L. M. , y Tarrío-García, M. (1983). Ganadería y estructura agraria en Chiapas. México: UAM-X.

Flores. J. M. (2013). Ganadería a medias en la Sierra de Santa Marta, Veracruz. Estudios Agrarios (199-220). México: SEDATU y Procuraduría Agraria. Recuperado de http://www.pa.gob.mx/publica/rev_57/analisis/ganaderia\%20 Jose\%20manuel.pdf

García Canal, M. I. (2005). Foucault y el poder. México: Universidad Autónoma Metropolitana.

García-Barrios, R. (2008). El desarrollo sustentable: el caso que emergió del nuevo orden “cooperativo”. En R. García-Barrios, B. De la Tejera Hernández y K. Appendini (coords.), Instituciones y desarrollo: ensayos sobre la complejidad del campo mexicano (pp. 33-64). México: UNAM. 
Giménez, G. (2007). Estudios sobre la cultura y las identidades sociales. México: Consejo Nacional para la Cultura y Las Artes e Iteso.

González Esponda, J. (2015). De la finca al ejido: historia que narra la fundación de ejidos en el primer valle de la Frailesca, 1915-1940. Chiapas: Consejo Estatal para las Culturas y las Artes de Chiapas y Universidad Autónoma de Chiapas.

Haesbaert, R. (2013). Del mito de la desterritorialización a la multiterritorialidad. Cultura y Representaciones Sociales, 14(27), 9-42. Recuperado de http://www.revistas.unam.mx/index.php/crs/article/view/41590

Instituto Nacional de Estadística y Geografía (INEGI). (2010). Censo de Población y Vivienda 2010. México: INEGI. Recuperado de https://www.inegi.org. $\mathrm{mx} /$ programas/ccpv/2010/

Kourí, E. (2010). Claroscuros de la reforma agraria mexicana. Revista Nexos, 396. Recuperado de https://www. nexos.com.mx/?p=14062

Kourí, E. (2015). La invención del ejido. Revista Nexos, 37(445), 54-61. Recuperado de https://biblat.unam.mx/es/revista/nexos-mexico-d-f/articulo/ la-invencion-del-ejido

Long, N. (2007). Sociología del desarrollo: una perspectiva centrada en el actor. México: CIESAS.

Max-Neef, M., Elizalde, A., y Hopenhayn, M. (1986). Desarrollo a escala humana: una opción para el futuro. Santiago de Chile: El Centro de Alternativas de Desarrollo y CEPAUR.

Mazurek, H. (2006). Espacio y territorio: instrumentos metodológicos de investigación social. Bolivia: Universidad de Postgrado para la Investigación Estratégica en Bolivia.

Merino Pérez, L., y Martínez Romero, A. E. (2014). A vuelo de pájaro. Las condiciones de las comunidades con bosques templados en México. México: Comisión Nacional para el Conocimiento y Uso de la Biodiversidad.

Minda-Batallas, P. A. (2002). Identidad y conflicto. La lucha por la tierra en la zona norte de la Provincia de Esmeraldas. Quito: Ediciones Abya-Yala.

Montañez Gómez, G., y Delgado Mahecha, O. (1998). Espacio, territorio y región: conceptos básicos para un proyecto nacional. Cuadernos de Geografía, 7(1-2), 121-134. Recuperado de https://acoge2000.homestead.com/files/ Montanez_y_Delgado._1998.pdf

Mora, G., de la. (2013). Servicios ambientales y propiedad. Análisis sociológicos de los procesos de apropiación de la tierra, el agua y el bosque en una comunidad agraria. México: Plaza y Valdés.

Morales, C., y Rivera Farfán, C. (2016). De peones a ejidatarios: identidades, naturaleza y cultura en la zona cafetalera del Soconusco, Escuintla, Chiapas. Gaia Ciencia. Edición Especial Cultura, Sociedad y Ambiente, 10(1), 42-52. Recuperado de http://periodicos.ufpb.br/index.php/gaia/article/ view/29142

Organización de las Naciones Unidas para la Alimentación y la Agricultura (FAO). (2003). Estudios sobre tenencia de la tierra. 3. Tenencia de la tierra y Desarrollo Rural. Roma, Italia. Recuperado de http://www.fao.org/3/y4307s/ y4307s05.htm\#bm05.1 
Parra, A. (2015). El concepto de identidad en la Modernidad Barroca en Bolívar Echeverría. Ciencia Política, 10(20), 75-106.

Pérez Castañeda J. C., y Mackinlay, H. (2015). ¿Existe una propiedad social agraria en México? Revista Polis, 11(1), 45-82. Recuperado de http://www.scielo.org. $\mathrm{mx} /$ scielo.php?script=sci_arttext\&pid=S1870-23332015000100045\&lng=es\&tlng=es

Porto-Gonçalves, C. (2009). De saberes y de territorios. Diversidad y emancipación a partir de la experiencia latino-americana. Polis, 22. Recuperado de http: / /journals.openedition.org/polis/2636

Procuraduría Agraria (PA) y Secretaría de Desarrollo Agrario, Territorial y Urbano (SEDATU). (2014). Ley Agraria y glosario de términos jurídicos-agrarios. México: Gobierno de la República Mexicana.

Ruiz-Gómez, M. M. (2006). El crecimiento de los asentamientos irregulares en áreas protegidas. La delegación Tlalpan. Investigaciones Geográficas, (60), 83-109. Recuperado de http://www.scielo.org.mx/scielo.php?script=sci_arttext\&pid=S0188-46112006000200006\&lng= es\&tlng=es

Scandroglio, B., López Martínez, J. S., y San José Sebastián, M. C. (2008). La teoría de la identidad social: una síntesis crítica de sus fundamentos, evidencias y controversias. Psicothema, 20(1), 80-89. Recuperado de https:// www.redalyc.org/articulo.oa?id=72720112\%253E\%2520ISSN\%25200214-9915

Secretaría de Desarrollo Agrario, Territorial y Urbano (SEDATU). (2017). Base de datos sobre predios no resueltos jurídicamente. Chiapas: Delegación Chiapas.

Secretaría de Desarrollo Territorial y Urbano, y Procuraduría Agraria. (2014). Ley Agraria y Glosario de Términos Jurídico-Agrarios. México. Recuperado de https: / / www.pa.gob.mx/pa/conoce/publicaciones/ley_glosario2014/glosario2014_25sep14_hq.pdf

Sen, A. (2000). Desarrollo y Libertad. Buenos Aires: Editorial Planeta.

Toledo, T. S. (2002). Fincas, poder y cultura en Simojovel, Chiapas. México: UNAM y Universidad Autónoma de Chiapas.

Torres-Mazuera, G., Fernández-Mendiburo, J., y Gómez Godoy, C. (2018). Informe sobre la jurisdicción agraria y los derechos humanos de los pueblos indígenas y campesinos en México. Fundación para el Debido Proceso DPLF.

Touraine, A. (1987). Actores sociales y sistemas políticos en América Latina. Chile: PREALC.

Trujillo-Díaz, A., Cruz-Morales, J., García-Barrios, L., y Pat-Fernández, L. (2018). Campesinos sin resolución agraria y en pugna interna en una reserva MAB: la difícil construcción territorial en Los Laureles, Chiapas, México. Revista Pueblos y Fronteras, 3(e-335), 1-29.

Uzeta, J. (2011). Mediaciones agraristas en dos municipios guanajuatenses: Atarjea y Xichú. Relaciones. Estudios de Historia y Sociedad, 32(125), 53-86. Recuperado de http://www.scielo.org.mx/scielo.php?script=sci_arttext\&pi$\mathrm{d}=\mathrm{S} 0185-39292011000100003 \& \operatorname{lng}=$ es\&tlng=es

Vasilachis, I. (2006). Estrategias de investigación cualitativa. Barcelona: Gedisa.

Zebadúa, E. (2011). Chiapas. Historia breve. México: Fondo de Cultura Económica y El Colegio de México. 